\title{
Processing of residual water by reverse osmosis
}

\begin{abstract}
Considering the problems related to issue of water resources, this study aims to analyze the wastewater recovery stage of the waste, from the reverse osmosis application, to replenish water in cooling towers. The present study was based on data obtained from industrial process of residual water recovery by reverse osmosis for replacement in cooling tower connected series to a heat exchanger system. Before the system, a daily continuous discharge (purge) of $7.81 \mathrm{~m}^{3} / \mathrm{h}$ was installed, which was required to maintain the silica concentrations inside the specified parameter. After the implementation of the new unit of reverse osmose, it was not necessary to perform a purge, due to the low concentration of solids dissolved in the water used for the replacement of water in the cooling tower. The reverse osmosis treatment of the tailings, in the initial stages, allowed supplying the water demand from the plant from the new system. The osmotic pressures of the processed water ranged from 0.53 to $1.61 \mathrm{kPa}$. These values were considered small due to the low silica concentrations. On average, the mass transfer coefficient was $0.26 \mathrm{~kg} \cdot \mathrm{m}^{-2} \mathrm{~h}^{-1} \mathrm{kPa}$.
\end{abstract}

Keywords: membrane separation, reverse osmosis, silica removal, tower cooling, water replacement, water reuse.
Volume 3 Issue 5 - 2019

\author{
Lilian de Oliveira Careta, Mauro Luiz Begnini, \\ Euclides Antônio Pereira Lima, José Roberto \\ Delalibera Finzer \\ Chemical Engineering Department, Uberaba University, Brazil
}

Correspondence: Mauro Luiz Begnini, Chemical,Av. Nenê Sabino, I80I, Uberaba, Minas Gerais, Brazil, Tel +553433 I95854, Email mauro.begnini@uniube.br

Received: October 06, 2019 | Published: October 18, 2019

\section{Introduction}

The company, target of this study, is a soybeans grains exporter. In May 2009, its first unit was inaugurated in Mato Grosso state, considered the main soybean grain producer in Brazil. In the production system, water cooling towers are used for reuse in heat exchangers. The cooling operation is accomplished by a combination of sensible heat transfer and the more relevant, evaporation of a small portion of the water. ${ }^{1}$ In cooling towers of water heat exchangers, the replacement water should be added, in order to compensate drag, evaporation and purging losses. ${ }^{2}$ In industry the large water consumers are cooling towers using $60-70 \%$ of the total fresh water demand. $^{3}$ Drag losses correspond between $0.1 \%$ and $0.3 \%$ of the water circulation rate for induced draft towers. If the replacement water contains dissolved salts, the same will accumulate due to the water evaporation in the cooling tower and a small amount must be eliminated, by purge, in order to avoid incrustation in the tubes of heat exchangers. ${ }^{4}$ At treating water for cooling towers the main materials removed are silica salts, total hardness, suspended solids, dyes, detergents, arsenic and microorganisms. ${ }^{5}$ In this paper, the aim was analyze the residual water recovery process by reverse osmosis for replacement in cooling towers, coupled with a heat exchangers system.

\section{Reverse osmosis process}

Current desalination processes require large amounts of energy as for reverse osmosis or thermal energy to generate steam for the evaporation process in thermal desalination plants and multi stage flash. But reverse osmosis is the most efficient desalination method. ${ }^{6}$ A reverse osmosis membrane is used in order to remove water from a solution using the application of external pressure. ${ }^{7}$

The osmotic pressure can be calculated by Equation $(1),{ }^{8}$

$$
\Pi=K_{S}+P_{S S}
$$

Where: Ks is the kinetic pressure of the solute molecules and Pss is the contribution to the overall pressure of the solute molecules interacting with other solute molecules. In case of a dilute solution this last term can be inconsiderated.

When two compartments, one with water and another with solution, are linked through a semi-permeable membrane, the water is free to flow between them, at a rate that depends on the permeability of the membrane for water. The forces actuating in the fluid flow are arrested only when the pressures of the water, on each side, are equal. However, if the pressures in both compartments have been adjusted no water will flow in either direction when the semi-permeable membrane alone separates the both compartments. Assuming there is no interaction between solute and solvent molecules, the problem could be solved treating the system similarly to an ideal gas mixture for a dilute solution. The liquid is considered a condensed gas. ${ }^{9}$ Therefore, Van't Hoff's law would immediately be followed. ${ }^{8}$ The osmotic pressure of a dilute aqueous solution can be obtained by Van't Hoff' law Equation (2): ${ }^{7}$

$$
\Pi=\frac{c \cdot R \cdot T}{M}
$$

Where: $\Pi$ is the osmotic pressure $(\mathrm{Pa}) ; c$ is the solute concentration $\left(\mathrm{kg} \cdot \mathrm{m}^{-3}\right) ; T$ is the absolute temperature $(\mathrm{K}) ; R$ is the gas constant and $M$ is the molecular weight.

Reverse osmosis occurs when $\Delta \Pi>\Delta P$, according to Equation (3), see Figure 1.,10,11

$$
J_{W}=k \cdot A(\Delta P-\Delta \Pi)
$$

Where: $\mathrm{J}\left(\mathrm{kgh}^{-1}\right)$ is the water flux, $\mathrm{K}\left(\mathrm{kg} \mathrm{m}^{-2} \mathrm{~h}^{-1} \mathrm{kPa}^{-1}\right)$ is the mass transfer coefficient, $\mathrm{A}\left(\mathrm{m}^{2}\right)$ is the membrane area, $\Delta \mathrm{P}(\mathrm{kPa})$ is the applied pressure and $\Delta \Pi(\mathrm{kPa})$ is the the osmotic pressure. In the last 15 years, in much of the world, plants have converted the process of reverse osmotic to use module of fine fiber of polyamide to seawater plants. ${ }^{12-15}$ the economical improvements and the membrane technology enhancement influenced the reduction on the prices of the desalinated water. This reduction was $\$ 2.0 / \mathrm{m}^{3}$ in 1988 to $\$ 0.5 / \mathrm{m}^{3}$ in 2014..$^{11,16}$ 


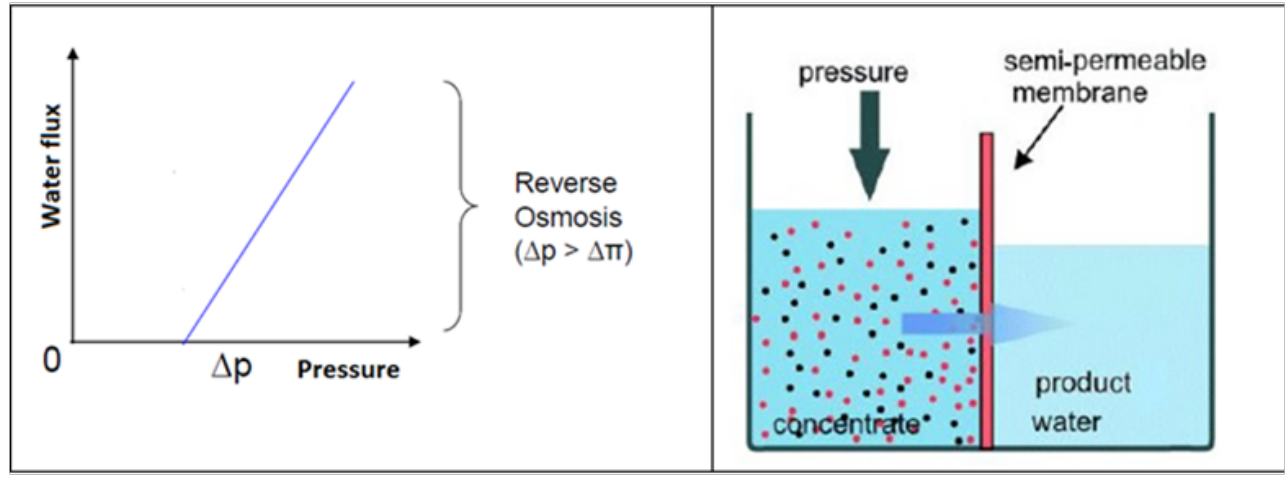

Figure I (A) Relation between water flux, osmotic pressure and transmenbrane hydrostatic; pressure; (B) System schematic.

\section{Water replacement in water cooling towers}

In the design of the cooling towers, special attention to three components is provided: the water distribution system, the internal packing and the eliminator of entrainment water. ${ }^{17}$ Replacement water can be quantified by mass balance, when defining the M, E, W and $B$ variables, respectively, replacement rates, evaporation, drag losses and purge, following the Equation (4).

$$
M=B+E+W
$$

Partial balance for the dissolved solids is given by Equation (5):

$$
M \cdot x_{M}=(B+W) \cdot x_{C}
$$

Where: $x_{C}$ and $\mathrm{x}_{\mathrm{M}}$ are, respectively, the salt mass fractions in the circulating and replacement waters.

Through the combination of the Equations (4) and (5) it was possible to define the Equation (6), which permits the purge (B) calculation.

$$
B=E \cdot\left(\frac{x_{M}}{x_{C}-x_{M}}\right)-W_{C}
$$

\section{Material and methods}

\section{Experimental system: membrane for reverse osmosis}

In this study, reverse osmosis membranes were originally developed for application in brackish water, using the model MWB840 (Mann+Hummel). The specifications of the membranes are: i) type: thin film composite; ii) material: polyamide (PA); iii) element configuration: spiral-wound; iv) Effective area of $37.2 \mathrm{~m}^{2}$; v) maximum permeate flow rate of $39.7 \mathrm{~m} 3 /$ day (quantified in bench test for processing of saline solution at $2000 \mathrm{mg} / \mathrm{L}$ ); vi) applied pressure of 1.5 MPa. The Figure 2 shows a schematic representation of the membrane system.

\section{Industrial system for water treatment and use}

Reactive silica dissolved in water dissociates in order to form a weak acid. The slight negative charge formed presents an affinity with the strong base anion resin and thus, this reactive silica can be removed, effectively, using a demineralization unit. However, the colloidal form of silica is a lightly harder to remove from feed water, due to its neutral charge. It should be mentioned that the reverse osmosis is an effective technology for the removing silica in both its reactive and non-reactive states. ${ }^{18}$ The method developed herein was based on the data obtained from the chemical analysis of different water types, which were from artesian wells, reverse osmosis waste water (water to feed boilers) and cooling tower. More attention was given to silica due to its high fouling power, with a maximum value of $150 \mathrm{ppm}$, specified in the circulation water. ${ }^{19}$ The company studied has six artesian wells with a total flow of $64.2 \mathrm{~m}^{3} / \mathrm{h}$, however, only five of them are in operation and one at rest. Thus, it is possible to count on a total flow for plant supply of approximately $54 \mathrm{~m}^{3} / \mathrm{h}$, with silica concentration of $12.9 \mathrm{ppm}$. The plant requires $36 \mathrm{~m}^{3} / \mathrm{h}$ of water to use in the steam production and in the reverse osmosis system with feed of $45 \mathrm{~m}^{3} / \mathrm{h}$ of water from the wells, generating, thus, a reject of $9 \mathrm{~m}^{3} / \mathrm{h}$. The demand for replacement water for the cooling tower is of $24.75 \mathrm{~m}^{3} / \mathrm{h}$, with water circulation of $1,900 \mathrm{~m} 3 / \mathrm{h}$ and purge of $7.81 \mathrm{~m}^{3} / \mathrm{h}$, in order to maintain the silica concentration in the operating range. The available water for this replacement, $9 \mathrm{~m}^{3} / \mathrm{h}$, it can be determined from the difference between that available from the wells and the one used for steam production.

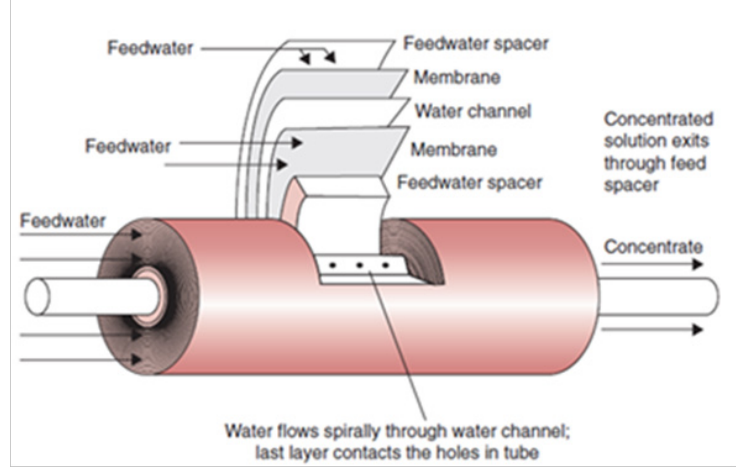

Figure 2 Spiral-wound membrane system (Singh and Helman, 20I4).

\section{Results and discussion}

Figure 3 provides the overview of the set of equipment with water utilization in the industrial process. Table 1 consists of the results of purge analysis of the water cooling tower, during seven consecutive days, which shows that the silica concentration was chose to maximum limit. Due to the occurrence of purge, among other demands (water evaporation and drag loss), the replacement water was required. In order to treat the waste from the reverse osmosis unit (RO) in obtaining boiler water, a reverse osmosis additional unit was installed. The direct use of the waste water, from the reverse osmosis waste, 
did not meet the replacement water requirements due to the amount and concentration of silica. Table 2 consists of silica concentration data obtained from measurements taken during four consecutive weeks in the RO unit. Table 3 shows the results of reverse osmosis waste water, water treatment for the boiler, and the available water from the wells $\left(9 \mathrm{~m}^{3} / \mathrm{h}\right)$ submitted to the third stage of reverse osmosis
(Figure 3). Table 3 is the result of silica concentration in the reverse osmosis waste water submitted to o the third stage of reverse osmosis, see Figure 1. Is must be stressed that data were obtained from the treatment of water to the boiler mixed with the water available from wells of $9 \mathrm{~m}^{3} / \mathrm{h}$.

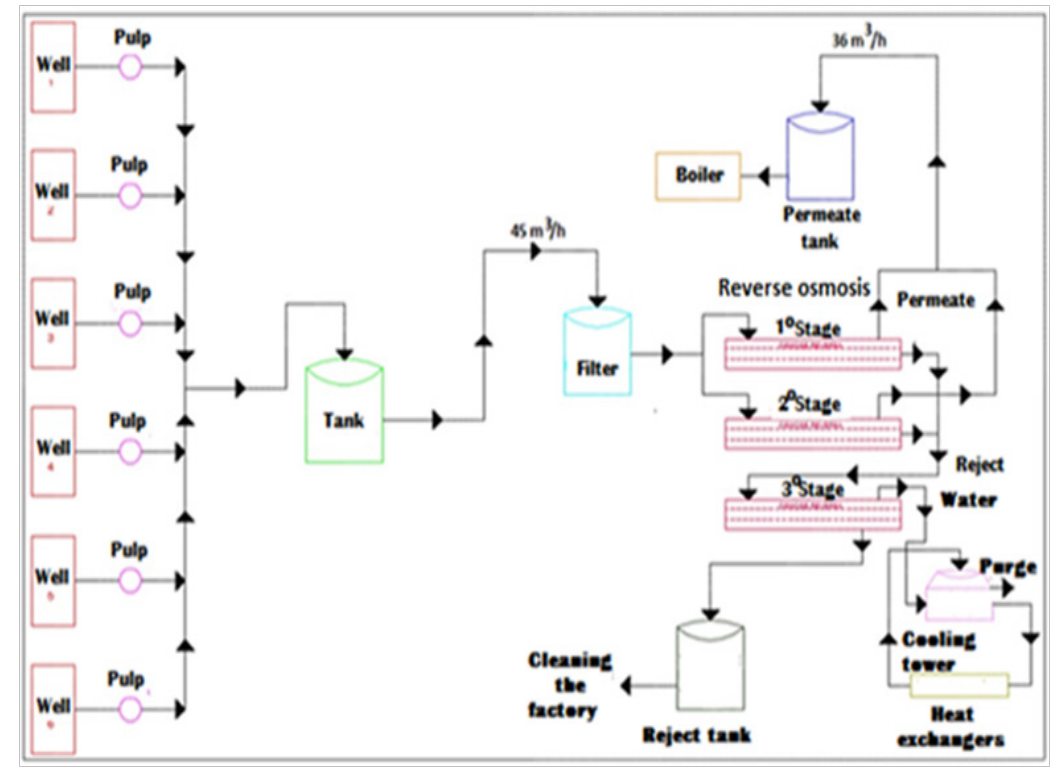

Figure 3 Well water collection system and using in the industrial process (Careta, 2017).

Table I Daily analysis of the water chemical composition (purge) of the cooling tower basin

\begin{tabular}{lllllllll}
\hline Composition & Value $\mathbf{1}^{\circ}$ day & Value $2^{\circ}$ day & Value $3^{\circ}$ day & Value $4^{\circ}$ day & Value & Value $6^{\circ}$ day & Value $7^{\circ}$ day & Average $^{\prime}$ \\
\hline Silica $(\mathrm{Ppm})$ & 162.7 & 156.3 & 152.3 & 151.3 & 152.7 & 159.3 & 149.5 & 154.87 \\
\hline
\end{tabular}

Table 2 Weekly analysis of silica concentration of the reverse osmosis wastewater

\begin{tabular}{llllll}
\hline Composition & Value I $^{\text {a }}$ week & Value $2^{\text {a }}$ week & Value $3^{\text {a }}$ week & Value $\mathbf{4}^{\text {a }}$ week & Average \\
\hline Silica - Ppm & 58.4 & 69.3 & 64.7 & 65.3 & 64.42 \\
\hline
\end{tabular}

Table 3 Silica concentration of water from the third stage of reverse osmosis

\begin{tabular}{llll}
\hline Composition & Value & Value & Average \\
\hline Silica - Ppm & 0.00 & 0.40 & 0.20 \\
\hline
\end{tabular}

After permanent replacement of water in the tower by the treated water in the third stage of reverse osmosis (6months), the silica content of the circulating water was measured. The results of measurements during the six even consecutive days are shown in the Table 4. It was found that the silica content presented lower than the maximum permissible to avoid the occurrence of fouling in heat exchangers. Therefore, the industrial system implemented met the water needs for the production process and enabled the heat exchangers could operate without occurrence of pipes incrustations.

Table 4 Analysis of silica concentration in the circulating water in the tower

\begin{tabular}{|c|c|c|c|c|c|c|c|}
\hline Composition & Value $I^{\circ}$ day & Value $2^{\circ}$ day & Value $3^{\circ}$ day & Value $4^{\circ}$ day & Value $5^{\circ}$ day & Value $6^{\circ}$ day & Average \\
\hline Silica - ppm & 103.89 & 94.7 & |l 4.6 & 72.4 & 65.2 & 50.8 & 83.59 \\
\hline
\end{tabular}




\section{Performance of reverse osmosis system in the treatment of water for the boiler}

Using the Equation (2), the osmotic pressure of a dilute aqueous solution can be obtained with the mean value of the silica concentration of the artesian wells.

$$
\Pi=\frac{c \cdot R \cdot T}{M}=\frac{0.0129 \mathrm{~kg} / \mathrm{m}^{3} \cdot 8.314 \mathrm{kPa} \cdot \mathrm{m}^{3} / \mathrm{kmol} \cdot K \cdot 298 \mathrm{~K}}{60 \mathrm{~kg} / \mathrm{kmol}}=0.53 \mathrm{kPa}
$$

Using the Equation (3), the mass transfer coefficient can be quantified using the arithmetic mean value of water processed in the two stages of reverse osmosis system, as shown below.

$$
k=\frac{J_{W}}{A(\Delta P-\Delta \Pi)}=\frac{18,000 \mathrm{~kg} / h}{37 \cdot 2 \mathrm{~m}^{2}\left(1.5 \cdot 10^{3}-0 \cdot 53\right) \mathrm{kPa}}=0.322 \mathrm{~kg} \cdot \mathrm{m}^{-2} h^{-1} \mathrm{kPa}{ }^{-1}
$$

\section{Performance of the reverse osmosis system in the treatment of tailings from preliminary stages}

Since there are $9 \mathrm{~m}^{3}$ of tailings water and $9 \mathrm{~m}^{3}$ of additional water in the wells, the mean of silica concentration in the water that feeds the third stage of reverse osmosis was equal to $(0.0129+0.0642) / 2=0.0390 \mathrm{~kg} / \mathrm{m}^{3}$. This result shows that it is possible to calculate the osmotic pressure of silica, as shown next.

$$
\Pi=\frac{c \cdot R \cdot T}{M}=\frac{0.0390 \mathrm{~kg} \cdot \mathrm{m}^{-3} \cdot 8.314 \mathrm{kPa} \cdot \mathrm{m}^{3} \cdot \mathrm{kmol}^{-1} \mathrm{~K}^{-1} \cdot 298 \mathrm{~K}}{60 \mathrm{~kg} \cdot \mathrm{kmol}^{-1}}=1.61 \mathrm{kPa}
$$

The influence of the osmotic pressure of silica was not relevant in the water separation, since it is very small compared to the hydraulic operating pressure. Using the Equation (3), the mass transfer coefficient can be quantified using the arithmetic mean value of water processed in the two stages of reverse osmosis system, as shown next.

$$
k=\frac{J_{W}}{A(\Delta P-\Delta \Pi)}=\frac{14,400 \mathrm{~kg} / h}{37 \cdot 2 \mathrm{~m}^{2}\left(1.5 \cdot 10^{3}-1.61\right) \mathrm{kPa}}=0.258 \mathrm{~kg} \cdot \mathrm{m}^{-2} h^{-1} \mathrm{kPa} a^{-1}
$$

It can be seen that the value obtained, previously, presented the same order of magnitude of the membranes of the first reverse osmosis stage.

\section{Process air in water cooling towers}

The air wet-bulb temperature is the variable that most influences the tower performance. ${ }^{20}$ The mass flow rate of air in the cooling towers can be calculated by means of the balance, the result of the modeling is expressed by Equation (7). ${ }^{4}$

$$
L \cdot c_{A L} \cdot\left(T_{t 2}-T_{L 1}\right)=G_{S}\left(H_{2}-H_{1}\right)
$$

Where: $G_{S}$ and $G_{S}$ are, respectively, the rates of water and air flow; $c_{\mathbb{L}}$ is the specific heat of the water; $T_{L 1}$ and $T_{t 2}$ are, respectively, the inlet and outlet temperatures of cooling water.

The average temperature in the Mato Grosso (Brazil) region is of $35^{\circ} \mathrm{C}$ and the relative air humidity is of $33 \%{ }^{21}$ Using a psychrometric chart, absolute air humidity and enthalpy $(\mathrm{H} 1)$, respectively, $0.012 \mathrm{~kg}$ $\mathrm{H}_{2} \mathrm{O} / \mathrm{kg}$ dry air and $64 \mathrm{~kJ} / \mathrm{kg}$ dry air were obtained. ${ }^{22}$ Applying the Equation (7), the air flow rate in the cooling tower was obtained, $1.75 \cdot 10^{6} \mathrm{~kg} / \mathrm{h}$. Since the air leaves the cooling towers in the saturation condition, the water evaporated by the mass balance was of $15.048 \mathrm{~m}^{3} / \mathrm{h}$. The water droplets percentage entrained by air was of $0.2 \%$ of the circulation rate, i.e., $1.9 \mathrm{~m}^{3} / \mathrm{h}$. The droplet percentage entrained air was of $0.2 \%$ of the circulation rate, i.e., $1.9 \mathrm{~m}^{3} / \mathrm{h}$. The replacement water due to the two losses is $16.9 \mathrm{~m}^{3} / \mathrm{h}$. As $9 \mathrm{~m}^{3} / \mathrm{h}$ from the wells and $9 \mathrm{~m}^{3} / \mathrm{h}$ from the third stage of reverse osmosis are available, the two losses are met by this demand, discounting the tailings from the third stage of reverse osmosis. Using Equation (3), it turns out that the purge would be negative, therefore unnecessary.

$$
B=E \cdot\left(\frac{x_{M}}{x_{C}-x_{M}}\right)-W_{C}=15,048\left(\frac{0,2}{150-0,2}\right)-1,9=-1,87 m^{3} / h
$$

\section{Conclusion}

Previously the system installation, a purge of $7.81 \mathrm{~m}^{3} / \mathrm{h}$ was required in order to maintain the silica concentrations within the specified parameters. After implementation of the third reverse osmosis unit, it was not necessary to perform a purge due to the low silica concentration dissolved in the water of cooling tower. The reverse osmosis treatment of the tailings, from the initial stages, supplied the water demand with the new reverse osmosis plant. The osmotic pressures of the processed water ranged from 0.53 to $1.61 \mathrm{kPa}$, which were small because the low silica concentrations. On average, the mass transfer coefficient in the reverse osmosis systems was of $0.29 \mathrm{~kg} \cdot \mathrm{m}^{-2} h^{-1} \mathrm{kPa}^{-1} .^{23}$

\section{Acknowledgments}

University of Uberaba for working conditions and CAPES for financial support.

\section{Conflicts of interest}

The authors declare that there is no conflict of interest.

\section{Funding}

FAPEMIG by bench rate.

\section{References}

1. Castro MM, Song TW, Pinto JM. Operational cost minimization in cooling water systems. Braz J Chem Eng. 2000;17(4):649-658.

2. Babcock GA. Maintaining Cooling Towers. ASHRAE Journal 2005;3:46-51

3. Stein KNE, Creusen RJM, Zijlstra M, et al. Membrane distillation of industrial cooling tower blowdown water. Water Resour. Ind. 2016;14:11-17.

4. Treybal RE. Mass Transfer Operations. New York. McGraw-Hill. 1981; p. 784.

5. Alcocer JJG. Method and integral system for treating water for cooling towers and processes requiring removal of silica from the water. Patent Application Publication. 2010;12-16.

6. AL-Zahrani A, Orfi J, AL-Suhaibani Z, et al. Thermodynamic analysis of a reverse osmosis desalination unit with energy recovery system. Procedia Engineer. 2012;33:404-414.

7. Singh RP, Heldman D.R. Introduction to food engineering. $5^{\text {th }}$ edn. Lincoln. Elsevier. 2014; p. 861.

8. Bowler MG. The physics of osmotic pressure. Eur J Phys. 2017;8:1-8.

9. Khare R. A new approach to derivation of Van't Hoff equation for osmotic pressure of a dilute solution. International Journal of Research in Science, Technology, Engineering \& Mathematics. 2015;11(2):172-174.

10. Nicoll PG. Forward osmosis - a brief introduction. World Congress on Desalination and Water Reuse. Tianjin, China. 2013;1-27. 
11. Fawal N. Parameters affecting desalination of seawater by reverse osmosis: Sampling; pretreatment; membrane processes; environmental impact. Doctoral thesis. University of Lille, Science and Technology. Lille. 2016.

12. Johnson J, Bucs M. Engineering aspects of reverse osmosis module design. Desalin Water Treat. 2010;15(1-3):236-248.

13. Lee KP, Arnot T, Mattia D. A review of reverse osmosis membrane materials for desalination-Development to date and future potential. $J$ Membrane Sci. 2010;370(1-2):1-22.

14. Abdelrasoul A, Doan H, Lohi A. Novel desalination RO membranes. InTech. 2017;37-57.

15. Sharma G, Kaur H. A Review on Recent Developments in Desalanisation by Forward Osmosis (FO) and Reverse Osmosis (RO). J Environ Sci Toxicol Food Technol. 2016;10(9):29-32.

16. Khulbe KC, Matsuura K. Recent Progresses in Preparation and Characterization of RO Membranes. JMSR. 2017;3(3):174-186.

17. Cutillas CG, Ramírez JR, Miralles ML. Optimum Design and Operation of an HVAC Cooling Tower for Energy and Water Conservation. Energies. 2017;10(3):1-27.

18. White JM, Masbate JL, Gare SG. Suez water technologies \& solutions. Trevose. 2017;1-7.

19. García AR, Martel NM, Nuez I. Short Review on Predicting Fouling in RO Desalination. Membranes. 2017;7(62):1-17.

20. Silva AF, Pessoa FLP, Sanches HL. The evaluation of the importance of additives in cooling tower operations. Braz $J$ Petrol Gas. 2017;11(1):1-14.

21. Peixoto DD, Vasconcelos TE, Thome Filho JJ. Diagnostic report aquifers purring, cloud jumping and utiariti in the state of Mato Grosso sedimentary basin of parecis. Geological Service of Brazil. 2012.

22. Fujita T, Tezuka S. Calculations on thermal performance of draft cooling towers. Ashrae Transactions. 1986;92:274-287.

23. Careta LC. de O. Reverse osmosis wastewater recovery for replacement in heat exchanger system. Masters dissertation. UNIUBE - Uberaba. 2017. 